\title{
ГНЕЗДОВАЯ БИОЛОГИЯ АЗИАТСКОЙ ДИКУШИ FALCIPENNIS FALCIPENNIS HARTLAUB, 1855 В НИЗКОГОРНОЙ ЧАСТИ АРЕАЛА
}

\author{
А. В. Андреев \\ ФГБУН Институт биологических проблем Севера ДВО РАН, г. Магадан \\ E-mail: alexandrea@mail.ru
}

\begin{abstract}
Индивидуальное прослеживание 18 самок дикуши, помеченных миниатюрными передатчиками, позволило охарактеризовать особенности гнездовой биологии вида в срединной части современного ареала. В условиях горной тайги Амгунь-Амурского междуречья весенняя плотность дикуши составляла 4-5 гнезд /км². Длительность репродуктивного периода от посещения самками токов до разлета выводков равнялась 120-135 дням. Распад весенних стай самок отмечен в конце апреля, расстояние между весенними и гнездовыми участками составило 250 1500 м (в среднем около 600 м), средние даты спаривания в популяции - 3-5 мая, инкубации - 18 мая - 14 июня, дисперсия выводков наблюдалась с середины сентября. В норме величина кладки достигала 5-7 яиц (в среднем 5.7), длительность периода инкубации 23.5 дня. В период насиживания самки покидали гнездо 2-3 раза в день, средняя длительность отлучек составляла 27.9 мин (от 15 до 115 мин), индекс плотности насиживания равен 0.95 . В течение всего периода инкубации в гнезде поддерживался температурный гомеостаз с градиентом

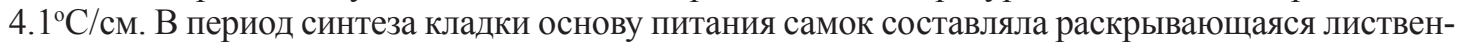
ничная хвоя, а в период инкубации - свежая еловая хвоя. Хищники разоряли около половины кладок в период инкубации и до начала дисперсии уничтожали около половины выводков.
\end{abstract}

Ключевые слова: азиатская дикуша, гнездование, успех размножения, Приамурье.

DOI: 10.34078/1814-0998-2019-4-83-94

\section{ВВЕДЕНИЕ}

Дикуша Falcipennis falcipennis Hartlaub, 1855 азиатский представитель трансберингийского рода «еловых рябчиков» - Falcipennis Elliot, 1864, распространенного в дальневосточной темнохвойной тайге и поясе бореальных лесов Северной Америки. Помимо эндемичного азиатского вида, род включает две североамериканские формы - менее специализированные в биотопическом отношении и шире распространенные - канадскую дикушу $F$. canadensis (Linnaeus, 1758) и горную дикушу F. franklinii (Douglas, 1829) (Потапов, 1985). В образе жизни и поведении трех сестринских видов много общего; их близкое родство отмечалось неоднократно (Yamashina, 1939; Степанян, 1962; Потапов, 1970). Оно проявляется в чертах внешней морфологии, половом диморфизме, полигамной системе размножения, хвоеядности в зимний период и «бесстрашии» дикуш в отношении человека. Последняя особенность позволяет отловить и пометить большинство, если не всех птиц локальной популяции. Отличительные черты азиатского вида за-

(C) Андреев А. В., 2019 ключаются в его тесной связи с аянской елью Picea jezoensis, хвоя которой служит чаще всего единственным источником питания птиц в течение большей части года, а также системе брачного поведения и связанных с нею особенностях внешней морфологии (Andreev et al., 2001). Азиатская дикуша - биотопический, сукцессионный вид, обитающий в условиях восточно-азиатской темнохвойной тайги с участием аянской ели, белокорой пихты Abies nephrolepis и лиственницы Larix gmelini (Klaus et al., 1995; Hafner, Andreev, 1998). В условиях интенсивных лесозаготовок и пирогенных трансформаций, характерных для современного этапа дальневосточного природопользования, ареал вида фрагментируется, а его локальные популяции деградируют на значительных площадях. По этой причине дикуша внесена в списки уязвимых видов регионального, национального и международного уровней (http:// www.iucnredlist.org).

В 1987-1997 гг. при поддержке Немецкого орнитологического общества и австрийского Института охотничьего хозяйства (Университет Вены) удалось подробно исследовать сезонную биологию азиатской дикуши в Комсомольском районе Хабаровского края. В общих чертах получен- 
ные результаты показаны в небольшой монографии (Hafner, Andreev, 1998) и более подробно - в статьях, описывающих брачное поведение дикуши (Andreev et al., 2001) и зимний период ее жизни (Andreev, Hafner, 2011). Особенностям гнездовой биологии азиатской дикуши посвящено лишь одно краткое сообщение (Andreev, 2005). Данная статья восполняет этот пробел: с доступной полнотой в ней исследованы особенности биологии азиатской дикуши в предгнездовой и инкубационный периоды.

\section{МЕТОДЫ И МАТЕРИАЛ}

Наблюдения выполнены в 1990-1997 гг. в срединной части современного ареала дикуши на северо-западной окраине Амгунь-Амурского мелкосопочника в Боктор-Харпинском междуречье (центр исследованного участка расположен в координатах $51^{\circ} 25^{\prime}$ с. ш., $137^{\circ} 23^{\prime}$ в. д.). Это пространство занято горно-таежной местностью, дренируемой левобережными притоками р. Горин.

Для целей исследования были отловлены и помечены 56 самок дикуши. Для отлова применяли описанный В. К. Арсеньевым, но несколько усовершенствованный мною «метод Дерсу» - телескопическую удочку длиной 2.5 м, снабженную кожаной петлей с безопасным (фиксированным) диаметром натяжения. В осеннее время птиц ловили на обочинах лесных дорог, весной - в ельниках с обилием муравьиных куч. Отловленных птиц взвешивали, измеряли длину крыла (по дуге изгиба), хвоста (от основания рулевых перьев), головы (от затылка до кончика клюва) и плюсны. Эти данные использовали для уточнения возраста птиц (табл. 1). Весной линейные измерения не позволяют надежно отделить взрослых самок (старше $23 \mathrm{mec)} \mathrm{от} \mathrm{молодых} \mathrm{(11} \mathrm{мес).} \mathrm{Более}$ удобны были масса тела и окраска оперения особей: у взрослых самок тон оперения более охристый при массе птиц 680-730 г, у молодых - сероватый при массе 640-650 г. В большинстве же случаев возраст птиц был известен благодаря их мечению в птенцовом возрасте.
Птиц метили с помощью цветных колец и импульсных передатчиков массой 10-12 г, работавших на частоте 150-151 МГц в течение 15 18 мес (http://www.biotrack.co.uk). Позднее прослеживали судьбу отдельных особей и их перемещения в различные сезоны года.

В токовой и предынкубационный периоды собрали данные по бюджету времени и питанию 5 самок дикуши (49.5 ч наблюдений). Во время гнездования были локализованы и описаны 18 гнезд, при этом только одно из них было найдено без помощи радиопередатчиков. Пеленгацию и поиск птиц осуществляли с помощью направленной Н-образной антенны размерами $26 \times 94$ см и УКВ-приемника прямого усиления «B + R» (Hafner, Andreev, 1998). C помощью подобной оснастки гарантированная дальность обнаружения птиц в таежных долинах составляла 2.5-3 км, на гребнях и вершинах гор - до 812 км. Использовали также более легкий всеволновый приемник «Yupiteru 7100», который в coчетании с упомянутой антенной давал хорошие результаты на удалениях до 1.5-2 км. Передатчики закрепляли на птицах с помощью стандартных ошейников (многожильная струна в силиконовой трубочке). С 25 апреля по 20 мая местоположение птиц определяли каждые 1-2 дня, координаты регистрировали с помощью GPS-приемника. Соединяя на карте крайние точки встреч, находили контуры индивидуальных участков особей в разные сезоны года. По расстоянию между центрами сезонных участков оценивали дальность перемещений, а также взаимное расположение токовых участков самцов и гнездовых участков самок.

При обнаружении гнезд описывали их положение в рельефе, состав наземной и древесной растительности. В целях минимизации угрозы со стороны четвероногих и пернатых хищников кладку посещали по возможности реже - либо 1, либо 2 раза: в момент обнаружения гнезда для его измерения и описания, затем, в избранных случаях - для установки датчиков температуры и активности птиц. Измеряли линейные параметры лотка, размеры и массу яиц. Благодаря

Таблица 1. Весовые и линейные характеристики самок дикуши разного возраста

Table 1. Mass and linear dimensions of adult and sub-adult females of the sharp-winged grouse

\begin{tabular}{|l|c|c|c|c|c|c|}
\hline \multicolumn{1}{|c|}{ Возраст } & $\begin{array}{c}\text { Кол-во } \\
\text { измерений }\end{array}$ & Масса тела, г & $\begin{array}{c}\text { Длина крыла, } \\
\text { мм }\end{array}$ & $\begin{array}{c}\text { Длина } \\
\text { хвоста, мм }\end{array}$ & $\begin{array}{c}\text { Длина головы, } \\
\text { мм }\end{array}$ & $\begin{array}{c}\text { Плюсна, } \\
\text { мм }\end{array}$ \\
\hline $\begin{array}{l}\text { Взрослые самки, май } \\
(23 \text { мес и более) }\end{array}$ & 16 & $712.6 \pm 20.1$ & $187.8 \pm 2.7$ & $104.4 \pm 6.7$ & $56.9 \pm 2.3$ & $46.0 \pm 1.8$ \\
\hline $\begin{array}{l}\text { Взрослые самки, сен- } \\
\text { тябрь (14 мес и более) }\end{array}$ & 10 & $662.7 \pm 38.1$ & $187.0 \pm 3.5$ & $105.5 \pm 5.5$ & $57.9 \pm 3.5$ & $47.3 \pm 2.7$ \\
\hline $\begin{array}{l}\text { Молодые самки, май } \\
(11 \text { мес) }\end{array}$ & 4 & $659.7 \pm 8.4$ & $186.5 \pm 0.7$ & $103.5 \pm 2.1$ & $54.9 \pm 3.0$ & - \\
\hline $\begin{array}{l}\text { Молодые самки, сен- } \\
\text { тябрь (3 мес) }\end{array}$ & 17 & $627.2 \pm 37.1$ & $184.1 \pm 3.4$ & $101.7 \pm 5.5$ & $57.4 \pm 1.7$ & $45.8 \pm 1.8$ \\
\hline
\end{tabular}


радиомаякам, несколько гнезд дикуши удалось найти на самых ранних стадиях формирования кладки. Для регистрации активности наседки в период откладки и насиживания яиц на дне гнездового лотка с помощью отрезка медной проволоки укрепляли датчик температуры (термистор) размерами $2 \times 8$ мм. Посредством тонкого кабеля термистор был соединен с цифровым логгером «Stowaway» (http://www.onsetcomp.com), размещенным в укрытом месте на удалении 1.52 м от гнезда. Частота опроса датчиков варьировала от 2 до 5 мин, а длительность непрерывной работы логгеров составила 5-25 дней. Таким способом записывали ход температуры на нижней поверхности кладки по центру гнездового лотка $\left(\mathrm{T}_{\mathrm{lc}}\right)$. Появление самки на гнезде сопровождалось характерными «всплесками» температуры, а уход - более или менее глубокими ее «провалами». При перемешивании яиц в кладке также регистрируются характерные всплески температуры датчика. По форме и частоте этих колебаний можно судить об активности насиживающей самки (см. рис. 2, 4). В период формирования кладки исследованы 5 гнезд дикуши (600 ч записей). После начала непрерывной инкубации записали и проанализировали процесс непрерывной инкубации в 4 гнездах дикуши в течение 1510 ч. Ход температуры воздуха (Тっ) в течение всего периода наблюдений регистрировали посредством термисторов и логгеров, помещаемых на высоте 1.2-1.5 м в укрытом от действия прямых солнечных лучей месте.

\section{РЕЗУЛЬТАТЫ}

Ландшафтные особенности района исследований. Климат Боктор-Харпинского междуречья умеренно таежный. Зимой и летом преобладали континентальные условия, весной и осенью постоянно ощущалось влияние дальневосточных морей. Снежный покров устанавливался в конце октября и разрушался в середине апреля - начале мая. Весной были характерны неустойчивые погоды с ночными снегопадами, дождливой и ветреной погодой. В период инкубации (середина мая - июнь) преобладали ясные погоды с температурой воздуха выше $+10 \ldots+15^{\circ} \mathrm{C}$. Во все весенние и летние месяцы при ясной погоде были выражены суточные перепады температур, достигавшие $20-25^{\circ} \mathrm{C}$. Рельеф местности, на которой располагался модельный участок площадью 10 км², контрастный, с отметками высот от 120-150 м в долинах до 250-350 м на покатых гребнях и седловинах гор. Северные склоны гор и верховья долин покрыты аянскими ельниками с примесью белокорой пихты и лиственницы. Возраст зрелых ельников 180-250 лет, местами - до 300-320 лет при высоте деревьев до 30-35 м. Возраст отдель- ных экземпляров лиственниц, разбросанных среди зрелых ельников, достигал 350-400 лет при высоте деревьев до 42-45 м (Klaus et al., 1995). На подгорьях преобладали елово-пихтовые и лиственнично-еловые леса с примесью березы Betula platyphylla и кедровой сосны Pinus koraiensis (в нижней и средней части склонов), местами - кедрового стланика Pinus pumila (на гребнях и вершинах гор). Южные склоны гор и днища долин заняты лиственничными и лиственничноберезовыми лесами с примесью ели. В разлогах гор, на высотах ниже 120 м н. у. м. распространены подгорные моховые болота, поросшие лиственницей, кустарниковой березой Betula frutico$s a$, багульником Ledum hypoleucum и кассандрой Chamaedaphne calyculata. Небольшие лиственничные мари были, как правило, окружены зрелыми ельниками. Во все сезоны года эти опушки служили излюбленным местообитанием дикуши.

В подлеске лиственничных боров преобладал рододендрон Rhododendron dauricum L. B наземном покрове, помимо мхов, повсеместно распространены канадский дерен Chamaepericlymenum canadense и брусника Vaccinium vitis-idaea.

В середине 1970-х гг. обширные участки зрелых ельников на седловинах отрогов Акта-Пукки были разрушены ветровалом, а в 1990-1992 гг. часть еловых массивов подверглась спонтанному усыханию. Позднее на ветровальных полях и в усыхающих ельниках развился многоярусный еловый подрост и разрослась малина Rubus sachalinensis. Выводки дикуши охотно посещали малинники в сентябре, а на участках елового подроста птицы подолгу держались зимой. Заболоченные долинные лиственничники и березняки с примесью аянской ели также служили местообитанием дикуши в снежный период (Андреев, 1990).

С начала 1980-х гг. район наших наблюдений находился в зоне интенсивных лесозаготовок. Покрытая сетью лесовозных дорог, местность была сравнительно легкодоступна. В течение 1990-2000 гг. значительные площади были пройдены сплошными вырубками. По данным космической съемки, наиболее быстрому сведению были подвержены лиственничные леса (Konovalenko, 2012).

Сезонные перемещения птиц и хронология репродуктивного сезона дикуши. В течение зимы дикуши постоянно и довольно широко перемещались. Особенно подвижны были молодые особи в возрасте 6-9 мес. С ноября по апрель дикуши объединялись в небольшие обоеполые стаи, весьма непостоянные по величине и составу (Andreev, Hafner, 2011). В районе наших исследований зимние конгрегации включали 26 птиц. Они встречались на привершинных участках склонов, седловинах гор и окраинах подгор- 
ных болот, как правило, среди зрелых или распадающихся ельников, а также в усыхающей темнохвойной тайге с участками бурелома и куртин елового подроста. По нашим наблюдениям, зимние стаи формировались за счет более подвижных молодых птиц, оседавших на некоторое время вблизи сравнительно более оседлых взрослых особей. В I декаде - середине апреля «зимние» стаи дикуши распадались. Первыми их покидали взрослые самцы, перемещавшиеся на токовые участки (Andreev et al., 2001). До конца апреля самки и молодые самцы оставались в «весенних» стаях, предпочитая привершинные части гор с елово-пихтовыми «крепями», обилием ветровальных стволов и муравейников. Весенние конгрегации включали 1-2 взрослых самок, 2-3 или более молодых самок и 1-2 молодых самцов. C началом интенсивного снеготаяния в III декаде апреля - начале мая весенние стаи дикуши распадались окончательно (табл. 2). Самки перемещались к токовым участкам самцов и будущих гнездовых территорий. Молодые самцы в это время широко передвигались в поисках подходящего участка для оседания и тока. Дальность весенних перемещений взрослых самцов варьировала в пределах 100-500 м, молодых самцов 300-700 м, самок - 250-1500 м (табл. 3).

В 1994-1997 гг. пик токования дикуши наблюдали через 11-14 дней после перехода среднесуточной температуры воздуха через ноль. Пик спаривания приходился на первую неделю мая. Молодые самки спаривались и приступали к гнездованию на 3-4 дня позднее взрослых.

Начало откладки яиц у взрослых самок приходилось в разные годы на период между 7 и 14 мая, в среднем 11 мая. Таким образом, период быстрого развития фолликулов занимал у взрослых самок от 5 до 10, в среднем 7 дней, у молодых - от 10 до 13 дней, в среднем 11 дней. Начало процесса непрерывной инкубации у взрослых самок приходилось на период между 13 и 21 мая,

Таблица 2. Календарь репродуктивного периода самок дикуши в 1990-1997 гг.

Table 2. Chronology of the sharp-winged grouse reproduction season in 1990-1997

\begin{tabular}{|c|c|c|c|c|}
\hline Событие & Ранний срок & Поздний срок & $\begin{array}{c}\text { Средняя дата } \\
\text { по многолетним данным }\end{array}$ & $\begin{array}{c}\text { Кол-во } \\
\text { наблюдений }\end{array}$ \\
\hline $\begin{array}{l}\text { Распад зимних стай: } \\
\text { разлет взрослых самцов }\end{array}$ & 2-10 апреля & 12-15 апреля & & 4 \\
\hline $\begin{array}{l}\text { Распад весенних стай: } \\
\text { разлет самок }\end{array}$ & 25 апреля & 1 мая & 28 апреля & 4 \\
\hline $\begin{array}{c}\text { Спаривание: } \\
\text { самки, ad. } \\
\text { самки, sad. }\end{array}$ & $\begin{array}{c}28 \text { апреля } \\
1 \text { мая }\end{array}$ & $\begin{array}{l}6 \text { мая } \\
9 \text { мая }\end{array}$ & $\begin{array}{l}3 \text { мая } \\
5 \text { мая }\end{array}$ & $\begin{array}{l}7 \\
5\end{array}$ \\
\hline $\begin{array}{l}\text { Начало откладки яиц: } \\
\text { самки, ad. } \\
\text { самки, sad. }\end{array}$ & $\begin{array}{c}7 \text { мая } \\
13 \text { мая }\end{array}$ & $\begin{array}{l}14 \text { мая } \\
19 \text { мая }\end{array}$ & $\begin{array}{l}11 \text { мая } \\
16 \text { мая }\end{array}$ & $\begin{array}{l}8 \\
6\end{array}$ \\
\hline $\begin{array}{l}\text { Начало инкубации: } \\
\text { самки, ad. } \\
\text { самки, sad. }\end{array}$ & $\begin{array}{l}13 \text { мая } \\
19 \text { мая }\end{array}$ & $\begin{array}{l}21 \text { мая } \\
26 \text { мая }\end{array}$ & $\begin{array}{l}18 \text { мая } \\
21 \text { мая }\end{array}$ & $\begin{array}{l}8 \\
6\end{array}$ \\
\hline $\begin{array}{l}\text { Появление птенцов: } \\
\text { самки, ad. } \\
\text { самки, sad. }\end{array}$ & $\begin{array}{c}6 \text { июня } \\
12 \text { июня }\end{array}$ & $\begin{array}{l}14 \text { июня } \\
19 \text { июня }\end{array}$ & $\begin{array}{l}10 \text { июня } \\
14 \text { июня }\end{array}$ & 14 \\
\hline Дисперсия выводков & $\begin{array}{l}\text { Середина } \\
\text { сентября }\end{array}$ & Середина октября & & 2 \\
\hline
\end{tabular}

Таблица 3. Дальность перемещений азиатской дикуши при смене участков обитания в зимне-весенний период, м

Table 3. Distances covered by the sharp-winged grouse by seasonal change of home ranges, $\mathrm{m}$

\begin{tabular}{|l|c|c|c|}
\hline Пол и возраст птиц & Лимиты, м & Среднее $\pm \mathrm{SD}$, м & Кол-во измерений \\
\hline Самцы, ad. & $100-500$ & $344 \pm 164$ & 8 \\
\hline Самцы, sad. & $300-700$ & $500 \pm 200$ & 3 \\
\hline Самки, ad. & $250-1300$ & $563 \pm 496$ & 4 \\
\hline Самки, sad. & $250-1500$ & $636 \pm 431$ & 7 \\
\hline
\end{tabular}


в среднем 18 мая, у молодых - между 19 и 26 мая, в среднем 21 мая (см. табл. 2). При одинаковой длительности периода инкубации в обеих возрастных группах (23.6 сут) в кладках взрослых самок птенцы появлялись между 6 и 14 июня, в среднем 10 июня, у молодых самок - между 12 и 19 июня, в среднем 14 июня.

Фенологически период распада зимних стай дикуши совпадал с началом снеготаяния, распад весенних конгрегаций самок - с периодом интенсивного разрушения снежного покрова (проталины занимали около 50\% площади), время спаривания - с полным разрушением снежного покрова, начало гнездования - с позеленением лиственницы, а начало процесса инкубации - с зацветанием даурского рододендрона.

Активность и питание самок в предынкубационный период. Дикушам свойственна полигиническая система размножения, но устойчивых коллективных токов ни один из видов этого рода не образует (Hjorth, 1970; Andreev et al., 2001). В Боктор-Харпинском междуречье токовые территории самцов располагались более или менее равномерно и, как правило, в линию, повторяя очертания опушек подгорных болот или узких гребней гор. Расстояние между ближайшими токующими самцами на пологих участках исследованной местности варьировало между 250 и 465 м, в среднем 330 \pm 64 м $(n=18)$.

Самцы начинали токование в «синих сумерках», за 45-60 мин до восхода солнца. Самки на токах появлялись также в предрассветные часы, но до восхода солнца и потепления атмосферы предпочитали оставаться в кронах деревьев. Поскольку самки дикуши приступают к размножению в возрасте $11 \mathrm{мес,} \mathrm{а} \mathrm{самцы,} \mathrm{как} \mathrm{правило,}$ только на 2-й или 3-й год жизни, то соотношение полов в репродуктивном пуле дикуши устанавливалось в пользу самок, большинство которых были молодыми особями. Самки в возрасте 2 лет и старше спаривались с партнерами предыдущего сезона, если те благополучно перезимовали. В иных случаях и взрослые, и молодые самки предпочитали самцов 3-летнего возраста - наиболее активных и заметных. На долю таких самцов приходилось наибольшее количество копуляций (Andreev et al., 2001).

В период формирования кладки, длящийся 5-8 дней, самки становились агрессивными по отношению друг к другу. Агрессия выражалась в громких территориальных позывках и «барабанных полетах»- перелетах с дерева на дерево с усиленно громким хлопаньем крыльев. Такое поведение я наблюдал только в утренних сумерках, когда взрослые самки, обитавшие на соседних участках, оказывались близко одна к другой. В период инкубации и вождения птенцов конфронтационного поведения самки не демонстрирова- ли. Как правило, гнездовые участки самок прилегали к токовым участкам самцов, их границы часто перекрывались. Расстояние между центром токового участка самца и гнездом варьировало от 105 до 515 м, в среднем оно составляло $217 \pm 98$ м $(\mathrm{n}=15)$ (рис. 1).

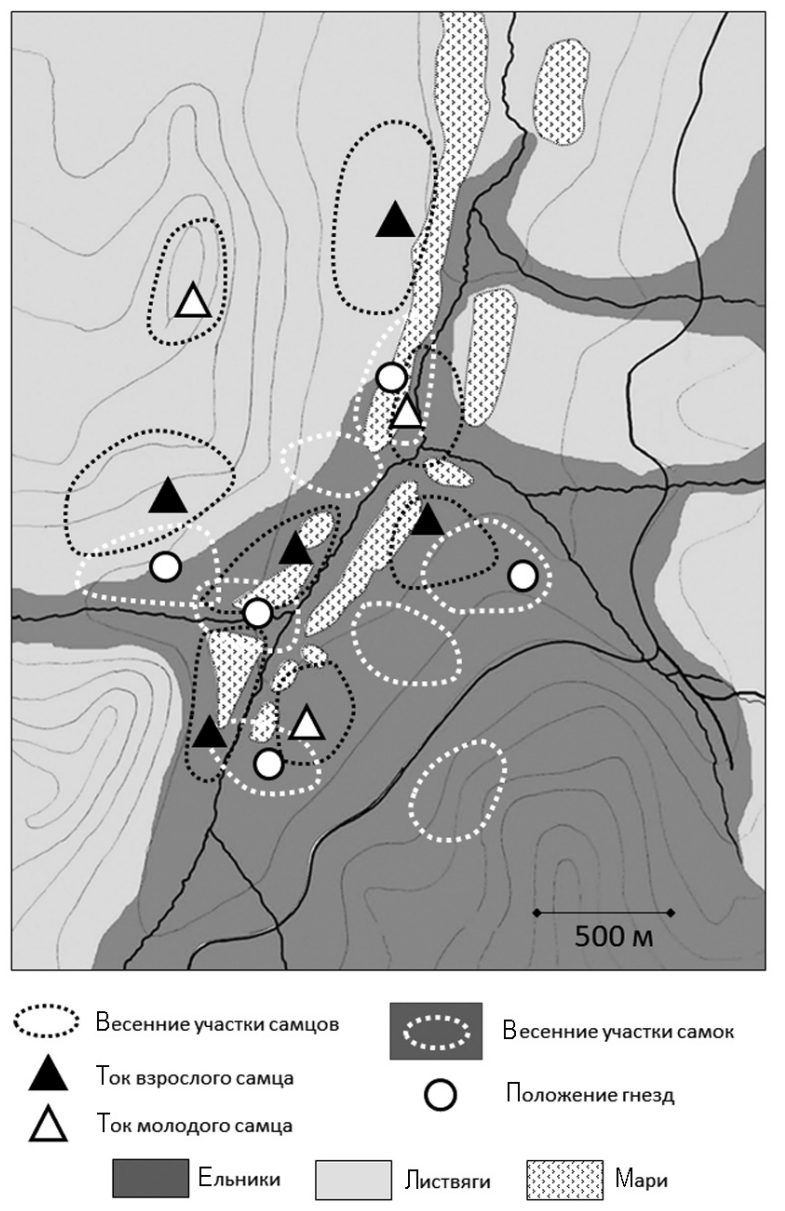

Puc. 1. Картосхема исследованной местности с указанием токовых и гнездовых участков дикуши в мае 1997 г

Fig. 1. Study plot chart, showing spring territories of males and nesting sites of hens in May 1997

Плотность размещения гнезд дикуши в среднем соответствовала плотности размещения токующих самцов. Расстояние между ближайшими гнездами варьировало от 170 до 450 м, в среднем - 265 497 м $(\mathrm{N}=11)$. Поскольку молодые самки в качестве брачного партнера чаще выбирали самцов в возрасте 3-4 лет, размещение гнездовых участков имело в некоторых случаях кластерный характер.

В период, предшествовавший распаду весенних стай (конец апреля), как и зимой, основу питания дикуши составляла еловая хвоя. Самки начинали кормиться в утренних сумерках за 4045 мин до восхода солнца. В течение 40-60 мин птицы наполняли зоб еловой хвоей, а затем сле- 
тали на землю. В течение дня они посещали оттаивающие муравейники или выворотни упавших стволов в поисках гастролитов. При продолжительности дня 16 ч самки проводили «на полу» в общей сложности до 12 ч, в кронах деревьев - до 4 ч, поднимаясь туда 4-6 раз в день для кормежки и отдыха (табл. 4).

Дикуши предпочитали средневозрастные ели высотой от 6 до 15 м, в среднем $15.7 \pm 7.9$ м (n= 25), где кормились и отдыхали на высоте от 2 до 15 м, в среднем $8.1 \pm 2.9$ м $(\mathrm{n}=25)$. Самки всегда ночевали на деревьях - иногда на пихтах, но чаще на средневозрастных елях высотой 12-15 м.

В начале мая в поисках гастролитов самки довольно часто появлялись на обочинах дорог. После посещения токов и спаривания пищевое поведение дикуши заметно менялось. В период формирования кладки птицы, регулярно и подолгу, питались раскрывающейся лиственничной хвоей. Ради этого корма самки поднимались в кроны средневозрастных (80-150 лет) и старых (150-375 лет) лиственниц высотой от 20

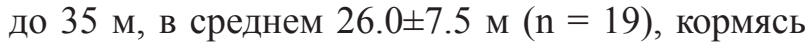
среди мощных ветвей кроны на высоте от 10 до 20 м, в среднем $16.1 \pm 3.7$ м $(\mathrm{N}=19)$. На старых лиственницах позеленение брахибластов происходило раньше, чем на молодых деревьях. В мае еловая хвоя по-прежнему составляла заметную долю в питании дикуши, но, по мере прогресса весны, время, проводимое дикушами в кронах елей, уменьшалось до 3-4 ч/сут, а время, проводимое на лиственницах, возрастало до 5-8 ч/сут (табл. 4). Самцы в весенний период на лиственницы не поднимались.

Биотопическое размещение гнезд и величина кладок. Дикуши устраивали гнезда в различных типах леса и на разных высотах. Наибольшее количество гнезд располагалось на склонах или седловинах гор (44\%) и у подножий склонов $(37 \%)$. На привершинных участках склонов и гребнях гор взрослые самки гнездились реже, чем годовалые: 19 и 25\% находок гнезд соответственно. Наименее притягательными для взрослых самок были лиственничные мари, где гнездились только годовалые самки (19\%). Взрослые самки предпочитали участки зрелых ельников или елово-лиственничных древостоев на подножьях склонов, определенно вытесняя оттуда молодых птиц на лиственнично-багульниковые мари (табл. 5).

Взрослые самки устраивали гнезда в хорошо укрытых местах - под прикрытием ветвей валежника или в углублении прикомлевой развилки корней высоких деревьев, обычно лиственниц, под обязательной защитой ветвей елового подроста. Такое расположение гнезда обеспечивает самке хорошее укрытие и обзор на удалении до $15-20 \mathrm{M}$.

Годовалые птицы, приступавшие к откладке яиц позднее взрослых, бывают вынуждены селиться в менее подходящих местах - чаще всего среди высоких зарослей багульника на марях. В подобном месте устроила, например, гнездо годовалая самка F5 в 1995 г. Ее кладка, состоявшая

Таблицุa 4. Дневная активность самок азиатской дикуши в предгнездовой период

Table 4. Diurnal activity of sharp-winged grouse females during the pre-nesting period

\begin{tabular}{|l|c|c|c|c|c|c|c|}
\hline \multirow{2}{*}{$\begin{array}{c}\text { Период } \\
\text { наблюдений }\end{array}$} & \multirow{2}{*}{$\begin{array}{c}\text { Длительность } \\
\text { наблюдений, ч }\end{array}$} & $\begin{array}{c}\text { Кол-во } \\
\text { птиц под } \\
\text { наблюдением }\end{array}$ & $\begin{array}{c}\text { Длина } \\
\text { ночи, ч }\end{array}$ & $\begin{array}{c}\text { Длина } \\
\text { дня, ч* }\end{array}$ & \multicolumn{3}{|c|}{ Бюджет времени в дневное время, } \\
\cline { 5 - 8 } & земле & $\begin{array}{c}\text { на } \\
\text { елях }\end{array}$ & на лиственницах \\
\hline ІІІ декада ап- & 16.3 & 3 & 8.0 & 16.0 & 76.5 & 24.5 & 0 \\
\hline І декада мая & 28.2 & 4 & 7.5 & 16.5 & 44.4 & 25.2 & 30.4 \\
\hline II декада мая & 5.3 & 3 & 7.0 & 17.0 & 33.3 & 19.2 & 47.5 \\
\hline
\end{tabular}

*B данном случае «длина дня» равна времени от восхода до захода солнца плюс 1.5 ч «гражданских» сумерек.

Таблица 5. Величина кладок и биотопическое размещение гнезд дикуши Table 5. Clutch size and habitat allocation of sharp-winged grouse nests

\begin{tabular}{|c|c|c|c|c|c|c|c|}
\hline \multirow[b]{2}{*}{ Возраст самок } & \multirow[b]{2}{*}{$\begin{array}{c}\text { Кол-во } \\
\text { измерений }\end{array}$} & \multicolumn{2}{|c|}{$\begin{array}{c}\text { Кол-во яиц } \\
\text { в полных кладках } \\
\end{array}$} & \multirow[b]{2}{*}{$\begin{array}{c}\text { Кол-во } \\
\text { находок }\end{array}$} & \multicolumn{3}{|c|}{$\begin{array}{c}\text { Биотопическое положение гнезд, } \\
\text { \% всех находок }\end{array}$} \\
\hline & & пределы & среднее & & $\begin{array}{c}\text { склоны } \\
\text { и седловины } \\
\text { гор }\end{array}$ & $\begin{array}{c}\text { подгорные } \\
\text { ельники }\end{array}$ & $\begin{array}{c}\text { багульниковые } \\
\text { мари }\end{array}$ \\
\hline Взрослые & 8 & $5-7$ & $6.0 \pm 0.7$ & 9 & 19 & 37 & 0 \\
\hline Годовалые & 7 & $5-6$ & $5.3 \pm 0.2$ & 7 & 25 & 0 & 19 \\
\hline Сумма/Среднее & 15 & & $5.7 \pm 0.7$ & 16 & 44 & 37 & 19 \\
\hline
\end{tabular}


из 5 яиц, была вскоре разорена хищниками. В последующие годы, приобретя более высокий статус, она селилась среди елово-пихтового леса в 300 м от мари. В 1996 г. ее кладка снова погибла, и только в 1997 г. ей удалось вывести птенцов.

В 15 завершенных кладках дикуши найдено от 5 до 7 яиц. Кладки взрослых самок содержали в среднем 6.3 яйца (от 5 до 7, $\mathrm{N}=9$ ). Годовалые самки откладывали в среднем 5.2 яйца (от 5 до 6, $\mathrm{N}=6$ ). Размеры и масса яиц взрослых самок несколько превышали аналогичные показатели молодых птиц: $45.5 \times 31.7$ мм, 23.4 г $(\mathrm{N}=25)$ и $44.8 \times$ 30.8 мм и 23.1 г $(\mathrm{N}=12)$ соответственно.

Взрослая самка F383 17.05.1997 г. завершила кладку из 7 яиц и приступила к насиживанию, но на следующий день ее гнездо было разорено соболем. В период между 24 и 30 мая эта птица сформировала новую кладку, состоявшую из 4 яиц, успешно ее инкубировала и 21 июня увела с гнезда птенцов. Этот случай показывает, что дикуша может создать кладку из 10-11 яиц, но в условиях Боктор-Харпинского междуречья ее репродуктивный потенциал реализуется с ограничениями. Возможно, на уровне популяции это позволяет возместить потерю кладок на начальных этапах периода гнездования.

Режим инкубации кладок и активность самок на гнездах. В период формирования кладок промежутки времени между откладкой яиц варьировали у разных особей от 23 до 54 ч, в среднем эти интервалы составляли $32.7 \pm 9.0$ ч $(\mathrm{n}=23)$ (рис. 2). В период кладки птицы посещали гнездо в утренние и полуденные часы. По мере прогресса формирования кладки периоды пребывания самки на гнезде возрастали от 1 до 5 ч. Связь между интервалами откладки яиц и температурой воздуха в предшествующие 1-2 дня не выявлена $\left(\mathrm{r}^{2}=0.02, \mathrm{~N}=17\right)$. Вместе с тем длительность синтеза очередного яйца зависела от его порядкового номера в кладке: наиболее длительные промежутки занимало формирование 3-го яйца, наиболее короткие - первых и последних (рис. 3).

Гнездо дикуши представляет собой простое углубление в почве диаметром 160-170 мм с небольшим количеством перьев, потерянных самкой при образовании наседного пятна.

Направляясь к гнезду для снесения очередного яйца, самка бывает возбужденной и становится заметной вследствие громкого «квохтанья», сопровождающего такие моменты. Эти возбужденные позывки нередко привлекают самца. Приближаясь к гнезду, он начинает токовать - как правило, в неурочное время и в малоподходящих местах. Устроившись на гнезде, самка способна быстро погасить возбуждение самца звуком негромкой «материнской» трели.

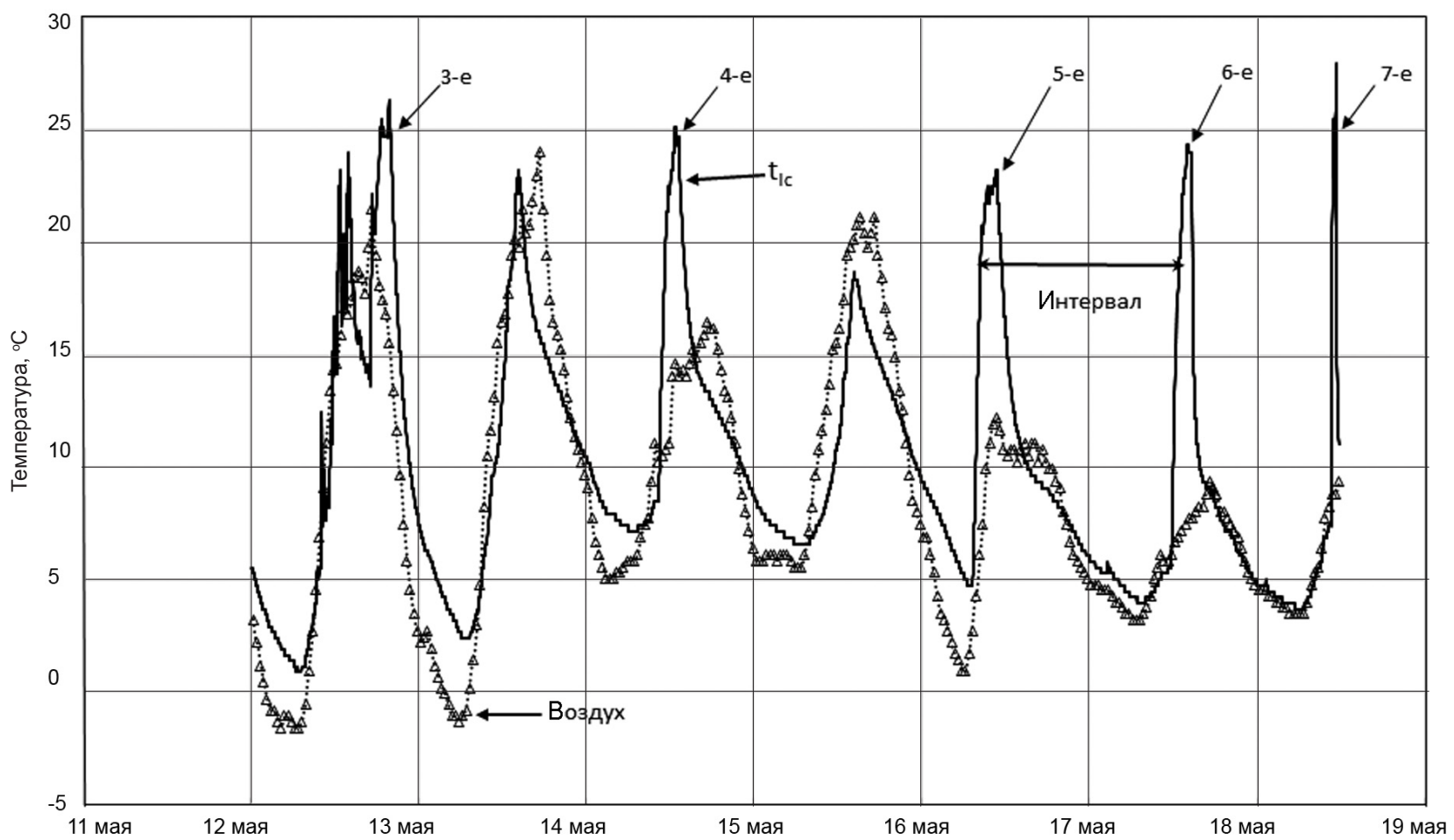

Puc. 2. Ход температуры в гнездовом лотке дикуши F383 в период формирования кладки. Цифрами над всплесками температуры отмечен порядковый номер яйца в кладке. В моменты снесения очередного яйца температура лотка $\left(\mathrm{T}_{\mathrm{lc}}\right)$ существенно выше температуры воздуха $\left(\mathrm{T}_{\mathrm{a}}\right)$

Fig. 2. Temperatures in the nest cup of Asian Grouse hen F383 during the laying period. Figures above peaks indicate order numbers of eggs in the clutch. At the moments of egg laying the nest cup temperature $\left(\mathrm{T}_{\mathrm{lc}}\right)$ essentially exceeds the ambient temperature $\left(\mathrm{T}_{\mathrm{a}}\right)$ 


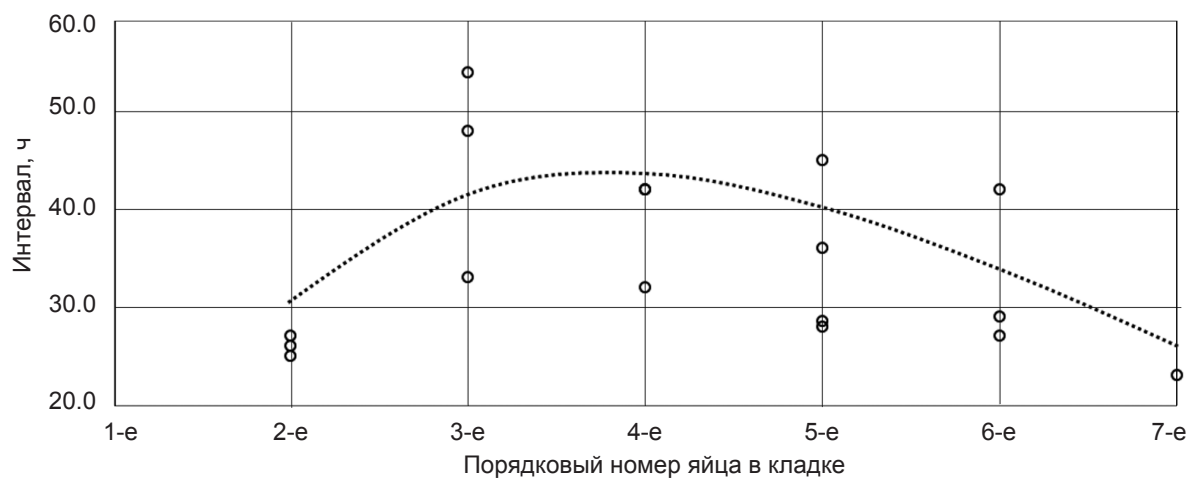

Puc. 3. Длительность интервалов между снесением яиц в период формирования кладки

Fig. 3. Length of intervals between egg laying during the clutch formation

Покидая незавершенную кладку, некоторые самки прикрывали ее хвоинками корейской сосны или сухими листьями осок.

По записям логгеров, от начала непрерывного насиживания кладки до выклева птенцов проходило 564-576 ч, в среднем $569 \pm 4.8$ ч $(\mathrm{N}=7)$, или 23.5-23.7 сут (рис. 4$)$.

Среднесуточные температуры лотка $\left(\mathrm{T}_{\mathrm{lc}}\right)$ изменялись в относительно небольших пределах. Например, в гнездах самок F5(97) и F145, для которых получены записи в течение всего периода инкубации, она изменялась от 21.9 до $24.3^{\circ} \mathrm{C}$, при среднем значении $25.3 \pm 1.5^{\circ} \mathrm{C}(\mathrm{N}=1104)$. При этом среднесуточная температура воздуха варьировала между 7.8 и $15.7^{\circ} \mathrm{C}$ при абсолютных колебаниях от -3 до $+31^{\circ} \mathrm{C}$. Между среднесуточными температурами воздуха и среднесуточными температурами лотка существовала положитель- ная корреляция средней силы: по мере нагрева атмосферы и прогрева почвы температура лотка несколько повышалась $\left(\mathrm{r}^{2}=+0.48, \mathrm{~N}=23\right)$.

Принимая диаметр яиц равным 3.1 см, температуру наседного пятна неворобьиных птиц равной $+40.2^{\circ} \mathrm{C}($ Andreev, 1999) и среднюю температуру лотка $+25.7^{\circ} \mathrm{C}$, найдем температурный градиент в насиживаемой кладке дикуши равным $4.7^{\circ} \mathrm{C} / \mathrm{cm}$. В таком градиенте пульсирует поток тепла, обеспечивающий развитие эмбрионов дикуши.

Поддерживая температурный гомеостаз кладок, наседки проводили на гнезде 22.523.0 ч/сут. Птицы оставляли гнездо 2-4 раза в день на 15-48 мин, при этом средняя длительность разовой отлучки составила 27.9 мин $(\mathrm{N}=$ 154; табл. 6). Моменты оставления гнезда и длительность отлучек не зависели от температуры

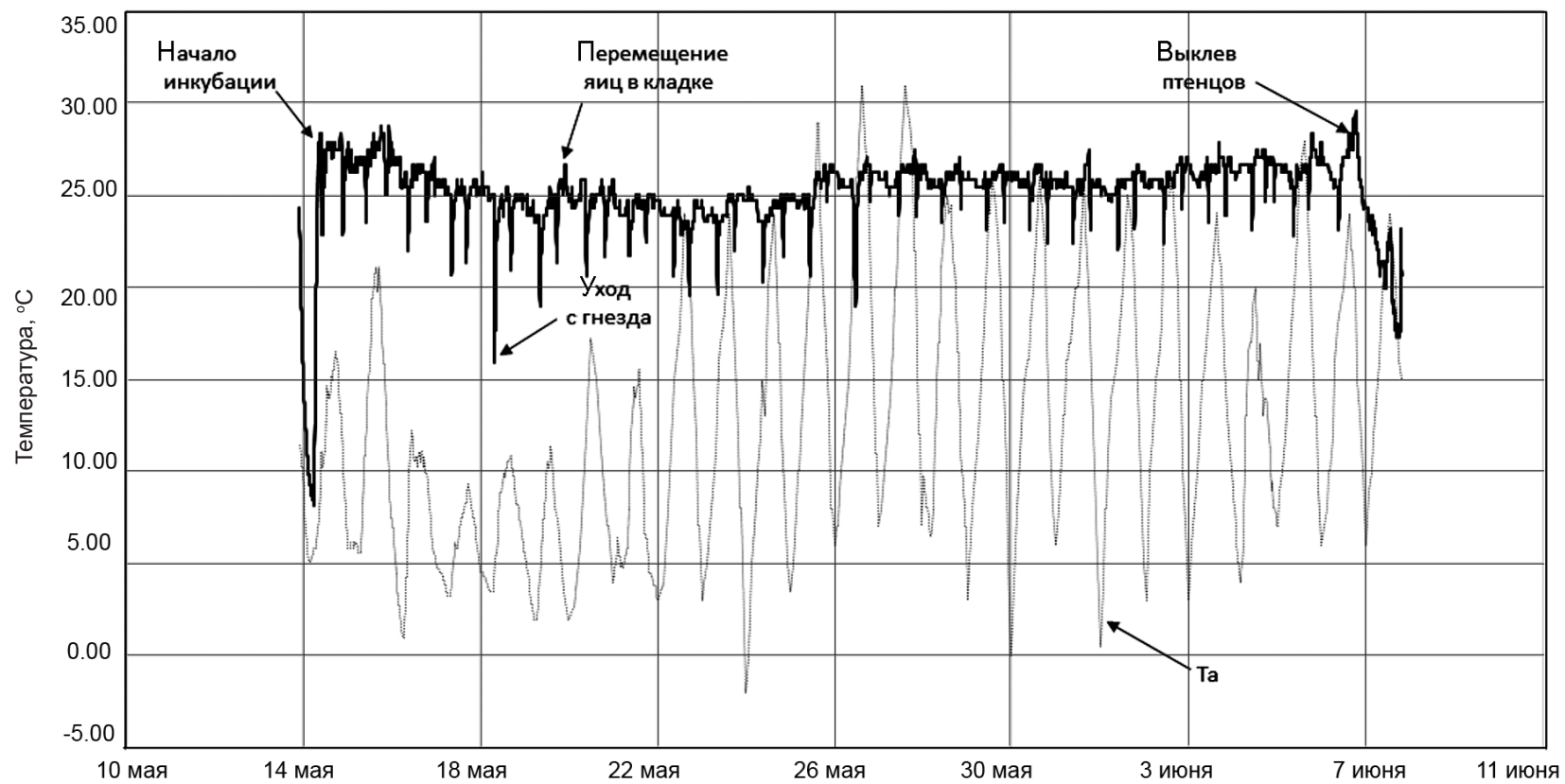

Puc. 4. Ход температуры воздуха ( $\left.\mathrm{T}_{\mathrm{a}}\right)$ и температуры лотка $\left(\mathrm{T}_{\mathrm{lc}}\right)$ в течение инкубационного периода самки F5 (1997 г.)

Fig. 4. Ambient $\left(\mathrm{T}_{\mathrm{a}}\right)$ and nest cup $\left(\mathrm{T}_{\mathrm{lc}}\right)$ temperatures during the entire period of incubation, hen $\mathrm{F} 5$ (1997) 
Таблица 6. Активность самок дикуши в период инкубации

Table 6. Activity of nesting hens during the incubation period

\begin{tabular}{|c|c|c|c|c|c|c|c|}
\hline $\begin{array}{l}\text { ID особей, } \\
\text { возраст }\end{array}$ & $\begin{array}{c}\text { Величина } \\
\text { кладки }\end{array}$ & $\begin{array}{c}\text { Даты } \\
\text { наблюдений }\end{array}$ & $\begin{array}{c}\text { Длитель- } \\
\text { ность } \\
\text { регистрации } \\
\text { данных, ч }\end{array}$ & $\begin{array}{l}\text { Кол-во отлучек } \\
\text { с гнезда в день }\end{array}$ & $\begin{array}{c}\text { Длительность } \\
\text { разовой } \\
\text { отлучки, мин } \\
(\mathrm{m} \pm \mathrm{SD} ; \mathrm{n})\end{array}$ & $\begin{array}{c}\text { Длительность } \\
\text { отсутствия } \\
\text { на гнезде } \\
\text { за весь период } \\
\text { инкубации, ч }\end{array}$ & $\begin{array}{c}\text { Плотность } \\
\text { насиживания }\end{array}$ \\
\hline $\begin{array}{l}\text { F5 (95), } \\
\text { ad. }\end{array}$ & 6 & $\begin{array}{c}6: 0014.05 \text { до } \\
7: 306.06\end{array}$ & 553.0 & 2 & $\begin{array}{c}30.5 \pm 0.8 \\
(15-48 ; n=46)\end{array}$ & 24.0 & 0.96 \\
\hline $\begin{array}{l}\text { F145, } \\
\text { sad. }\end{array}$ & 5 & $\begin{array}{c}9: 4020.05 \text { до } \\
\text { 19:00 } 12.06 \\
\end{array}$ & 537 & $2-3$ & $\begin{array}{c}27.0 \pm 15.0 \\
(15-115 ; \mathrm{n}=65)\end{array}$ & 28.6 & 0.95 \\
\hline $\begin{array}{l}\text { F383, } \\
\text { ad.* }\end{array}$ & 4 & $\begin{array}{c}19: 308.06 \text { до } \\
15: 1021.06\end{array}$ & 308 & $3-4$ & $\begin{array}{c}26.6 \pm 7.8 \\
(15-45 ; n=43)\end{array}$ & 19.1 & 0.95 \\
\hline Среднее & & & & 2.8 & 27.9 & 23.9 & 0.957 \\
\hline
\end{tabular}

* Повторная кладка.

воздуха, но отчетливо совпадали с моментами ее быстрого изменения - возрастания в утренние часы и понижения - в вечерние. За время отсутствия самки на гнезде температура лотка падала на $3.5-6^{\circ} \mathrm{C}$ (в среднем до $22.4 \pm 1.6^{\circ} \mathrm{C}$ ).

В разные дни взрослая самка F5 уходила с гнезда утром, начиная с $5^{30} \ldots 6^{00}$ до $8^{30} \ldots 9^{00}$. Во второй половине дня, начиная с $13^{45} \ldots 14^{15}$ до $18^{45} \ldots 19^{15}$ (время локальное GMT + 9 ч). Общая продолжительность отлучек в трех исследованных гнездах варьировала между 60 и 88 мин/сут, в среднем она составила 78 мин/сут $(\mathrm{n}=147)$. Индекс плотности насиживания (отношение общей длительности пребывания на гнезде к длительности периода инкубации) во всех случаях оставался высоким и варьировал между 0.95 и 0.96 .

Отлучаясь с гнезда, наседки отходили на несколько шагов и взлетали в кроны деревьев, удаляясь на 50-80 м. На деревьях птицы торопливо кормились в еловых кронах, одновременно прочищая кишечник. Вследствие такого поведения дикуша не оставляет на земле характерных комков экскрементов грушевидной формы, которые у других тетеревиных птиц позволяют «вычислить» местонахождение гнезда. В период инкубации дикуши продолжали питаться и лиственничной хвоей, но чаще всего самки объедали концы еловых ветвей, наполняя зоб объемистыми пучками сочных почек. Объем поедаемой пищи определенно не компенсировал пищевые потребности самок: к моменту появления птенцов они теряли до 20\% массы тела. Например, в 1996 г. две взрослые самки, утратившие свои выводки к середине июня, весили 580 и 530 г.

Успех гнездования. Только в 9 кладках из 17 найденных инкубация прошла успешно и закончилась появлением птенцов. Успех гнез- дования за весь период наблюдений составил, таким образом, 53\%. При этом из 40 успешно инкубированных яиц на свет появилось 37 птенцов, т. е. успех инкубации достигал 92.5\%. Из 8 погибших кладок 5 были разорены наземными или пернатыми хищниками: соболем (3 кладки), белкой (1 кладка) и кедровкой (1 кладка). Еще две кладки погибли вместе с насиживающими птицами при нападении соболя. Одна незавершенная кладка была брошена насиживающей птицей во время длительного снегопада, случившегося 15 мая 1994 г. Потеря кладок среди молодых птиц составила 57\%, среди взрослых $-40 \%$.

Из 9 выводков, покинувших гнезда, 5 погибли полностью в течение первых 2 нед жизни. Пернатые хищники - болотный лунь, сарыч, тетеревятник и бородатая неясыть - постоянно встречались в районе наблюдений и составляли, судя по всему, основную угрозу для выводков дикуши. В итоге только 4 взрослые самки смогли сохранить выводки и поднять молодых на крыло до начала дисперсии (середина сентября - начало октября). Как видим, в условиях БокторХарпинского междуречья суммарная смертность самок и птенцов в репродуктивный период была выше $75 \%$.

\section{ОБСУЖДЕНИЕ}

Азиатская дикуша населяет относительно небольшой притихоокеанский ареал площадью около 1.1 млн км², совпадающий с ареалом аянской ели. В современных условиях вид населяет пространство протяженностью около 1800 км с севера на юг (между 43 и 59 с. ш.) и около 1500 км с запада на восток (между 121 и $144^{\circ}$ в. д.). Вид встречается на высотах от 20-400 в низкогорноравнинной части ареала до 1200-1500 м н. у. м. в хребтах Приморья, Приамурья и Приохотья, 
включая о. Сахалин (Klaus, Andreev, 2003). На этом пространстве климатические условия и ход весенних событий заметно различаются. Упоминаемая ранее хронология репродуктивного цикла дикуши относится к низкогорной (срединной) части ее ареала.

Ведя отсчет событий от 20 апреля (в 1990-х гг. примерно в это время происходил переход среднесуточной температуры воздуха через ноль, в настоящее время, под данным метеостанций «Боктор» и «Горин», он сдвинулся к 12-15 апреля, www.rp5.ru), видим, что до периода копуляции проходило около 14 дней, а до начала периода гнездования (кладка яиц с 11-16 мая) - 2126 дней. От начала формирования кладки до появления выводков во II декаде июня проходило еще 30-32 дня. Поскольку увеличение массы тела и линейных показателей молодых птиц заканчивалось к 60-65-дневному возрасту, т. е. к I декаде сентября (Hafner, Andreev, 1998), можем заключить, что общая длительность репродуктивного сезона дикуши от момента копуляции до завершения роста птенцов составила 120-125 дней. При этом до времени распада выводков в середине конце сентября оставалось 15-30 дней, а до установления устойчивого снежного покрова (конец октября) - еще около месяца. Таким образом, возможность существования дикуши в более суровых климатических условиях - на западе и севере современного ареала определяется периодом протяженностью 135-150 дней. К сожалению, достоверных сведений по фенологии азиатской дикуши в других частях ее ареала пока нет.

В период токования самцов и формирования кладок самками все три вида дикуши территориальны. У североамериканских видов территориальное поведение самок выражено сильнее, чем у азиатского вида. Оно проявляется в громких позывках и агрессивном поведении по отношению к конспецифичным самкам. У горной и канадской дикуш территориальные позывки хорошо выражены в любое время дня, что позволяет проводить весенние учеты этих видов с помощью проигрывания звукозаписи (Herzog, Boag, 1977; Robinson, 1980). На значительной части ареала американские дикуши обитают в монотонных, часто мертвопокровных, сосняках, и весенняя агрессивность самок объясняется недостатком свежих кормов в период синтеза кладок (Naylor, Bendell, 1989; Boag, Schroeder, 1992). У азиатской дикуши весной отмечены элементы территориального поведения, но проявляется оно не регулярно и выражено не столь ярко, как у американских видов. Благодаря появлению свежей лиственничной хвои в начале мая, азиатская дикуша имеет возможность приступить к формированию кладки до того, как появятся проростки наземных растений. Связь азиатской дикуши с лиственницей весьма устойчива и сохраняется до поздней осени во всем ареале. Эта птица в такой же степени «лиственничный рябчик», как и «еловый». У североамериканских видов на большей части ареала подобного «козыря» нет, и дефицит весенних кормов представляет для них существенную проблему. Вместе с тем в период инкубации все три вида дикуши употребляют в пищу объемистые «почки» еловой хвои, появляющиеся на концах ветвей в конце мая - начале июня (Herzog, 1978; Robinson, 1980). Если весеннее питание лиственницей отличает азиатскую дикушу от американских видов, то еловая хвоя объединяет их в период насиживания. Другая общая черта - заметное исхудание наседок во время инкубации: взрослые самки американских дикуш теряют за этот период до 25\% начальной массы тела, молодые - до 18\% (Ellison, Weeden, 1979; Boag, Schroeder, 1992).

Территориализм самок азиатской дикуши выглядит реликтовой чертой. В условиях дальневосточной тайги он обеспечивает поддержание более равномерного распределения гнездовых участков, что, в свою очередь, должно вести к снижению вероятности гибели кладок от хищников.

В изученной местности среднее расстояние между соседними гнездами азиатской дикуши составило $265 \pm 97$ м. При таких расстояниях потенциальную биотопическую плотность гнездования вида следует ожидать равной 912 гнезд/км². Однако в районе наблюдений размещение гнездовых участков дикуши носило неравномерный характер, и, по данным картирования, плотность гнездования составила 45 гнезд/км². Допуская равномерное соотношение полов, можем оценить весеннюю плотность вида в исследованной местности в пределах 8-10 ос./км². Судя по картосхеме, приводимой Ю. Б. Пукинским (2003), среднее расстояние между центрами соседних участков самок дикуши на Бикине составляло $409 \pm 152$ м, что также приводит к оценкам примерно 4-5 гнезд/км².

Величина завершенных кладок азиатской дикуши в районе наблюдений варьировала между 5 и 7 яйцами. В других частях ареала найдены кладки такой же или несколько большей величины: 6 яиц на берегу Тугурского залива (А. А. Услонцев, личн. сообщ.), 7 яиц в бассейне Бикина (Пукинский, 2003), 8 яиц на Сахалине (Taka-Tsukasa, 1932). Средняя величина кладки канадской дикуши также варьирует между 5 и 7 яйцами: у взрослых самок $6.6 \pm 1.1$ яйца, у молодых - 5.0 1.1 (Keppie, 1982).

Базовые параметры репродуктивного процесса у трех видов дикуши близко совпадают. В частности, средний интервал откладки яиц составляет у азиатской дикуши 32.7 ч, у американской - 33.6 ч (McCourt et al., 1973), длительность периода инкубации у всех видов одинакова 23.5 сут (Boag, Schroeder, 1992). Масса свежего 
яйца у азиатской дикуши равна 23.3 г, или 3.3$3.5 \%$ средней массы тела, масса полной кладки варьирует от $18 \%$ массы тела у молодых самок до $23 \%$ у взрослых. Соответствующие показатели канадской дикуши равны 22.0 г для массы яиц, или 3.3-4.2\% средней массы тела, и 18-23\% для полной кладки (Keppie,1982).

Статистика данных, описывающих успех гнездования дикуши, не велика, но для данного вида она собрана впервые. В период инкубации азиатская дикуша крайне уязвима: в районе наблюдений потери кладок достигли 53\%. При этом успех гнездования молодых птиц был заметно ниже, чем у взрослых. В целом смертность гнезд и выводков в боктор-харпинской популяции дикуши достигала $75 \%$. Столь низкий успех размножения дикуши можно объяснить обилием пернатых и четвероногих хищников (тетеревятник Accipiter gentilis, бородатая неясыть Strix nebulosa, соболь Martes zibellina), привлекаемых в данную местность высокой численностью рябчика Tetrastes bonasia, благоденствующего в условиях обилия зарастающих вырубок, а также лесных полевок, достигающих высокой численности в годы урожая корейской сосны, кедрового стланика и аянской ели. В местностях с менее насыщенной лесной биотой, например, в горных хребтах Приамурья близ верхней границы леса, успех размножения дикуши окажется, скорее всего, более высоким.

Немецкие коллеги 3. Клаус, Ф. Хафнер и Х. Госов поддержали данную работу на всех ее этапах как финансово, так и участием в полевых работах. В организации и проведении последних большую помощь оказали комсомольчане В. С. Соловьев, А. М. Услонцев и Д. Кришкевич. Считаю приятным долгом выразить им свою искреннюю признательность.

\section{ЛИТЕРАТУРА}

Андреев A. В. Наблюдения по зимней биологии дикуши (Falcipennis falcipennis) в Приамурье // Зоол. журн. 1990. 69, 3. С. 69-80.

Потапов Р. Л. Отряд курообразные (Galliformes). Семейство тетеревиные (Tetraonidae). Л. : Наука, 1985. $638 \mathrm{c.}$.

Потапов Р. Л. Сравнительный обзор дикуш (роды Falcipennis и Canachites, Tetraonidae) Азии и Северной Америки // Тр. Зоол. ин-та АН СССР. 1970. Т. 47. C. 205-235.

Пукинский Ю. Б. Гнездовая жизнь птиц бассейна реки Бикин. СПб. : Изд-во СПбГУ, 2003. 316 с. (Тр. СПб. О-ва естествоиспытателей. Сер. 4, т. 86).

Степанян Л. С. Систематические взаимоотношения дикуши и канадского рябчика // Орнитология. 1962. № 5. C. 368-371.

Andreev A. V., Hafner, F., Klaus S., Gossow H. Displaying behaviour and mating system in the Siberian Spruce Grouse (Falcipennis falcipennis Hartlaub,
1855) // Journal für Ornithologie. 2001. Vol. 142. P. 404-424.

Andreev A. $V$. Ecological energetics and survival of birds in extreme environments / XXII IOC plenary lectures // Ostrich. 1999. Vol. 70 (1). P. 13-22.

Andreev $A$. $V$. Nesting biology of Asian Spruce Grouse / $X^{\text {th }}$ Int. Symposium on Grouse $26-30^{\text {th }}$ Sep. 2005. Luchon. 2005. P. 3-4.

Andreev A. V., Hafner F. Winter biology of the Siberian Grouse Falcipennis falcipennis // Ornithological Science. 2011. 10. P. 87-97.

Boag D. A., Schroeder M. A. Spruce Grouse // The Birds of North America / eds. A. Poole, P. Stettenheim, F. Gill. Philadelphia, 1992. No. 5. 27 p.

Ellison L. N., Weeden R. B. Seasonal and local weights of Alaskan Spruce Grouse // Journal of Wildlife Management. 1979. No. 43. P. 176-183.

Hafner F., Andreev A. V. Das Sichelhuhn. Klagenfurt St. Petersburg, 1998. $118 \mathrm{~s}$.

Herzog $P$. $W$. Food selection by female Spruce Grouse during incubation // Journal of Wildlife Management. 1978. No. 42. P. 632-636.

Herzog P. W. Boag D. A. Seasonal changes in aggressive behavior of female Spruce Grouse // Canadian Journal of Zoology. 1977. No. 55. P. 1734-1739.

Hjorth I. Reproductive behaviour in Tetraonidae with special reference to males // Viltrevy. 1970. Vol. 7, No. 4. P. 183-596.

Keppie D. M. A difference in production and associated events in two races of spruce grouse // Canadian Journal of Zoology. 1982. Vol. 60 (9). P. 2116-2123.

Klaus S., Lieser M., Suchant R., Andreev A. V. Beitrag zur Kenntnis der Waldvegetation in der fernostlischen Taiga Russlands (Amurregion) // Allgemeine Forstzeitschruft. 1995. 14. S. 744-748.

Klaus S., Andreev A. V. Falcipennis falcipennis (Hartlaub, 1855) Sichelhuhn // Atlas der Verbreitung palaearktischer Vögel. 2003. No. 20. S. 1-5.

Konovalenko $K$. The Influence of forest cover changes in Russian Far East on the population of Siberian Spruce Grouse : Ms. thesis. Albert-Ludwig Universität : Faculty of Forest and Environmental Sciences, 2012.91 p.

McCourt K. H., Boag D. A., Keppie D. M. Female Spruce Grouse activity during laying and incubation // The Auk. 1973. Vol. 90. P. 619-623.

Naylor B. J., Bendell J. F. Clutch size and egg size of Spruce Grouse in relation to spring diet, food supply, and endogenous resources // Can. J. Zool. 1989. Vol. 67. P. 969-980.

Robinson W. L. Fool Hen: the Spruce Grouse on the Yellow Dog Plains. Madison : Univ. Wisconsin Press, 1980. 210 p.

Taka-Tsukasa N. The birds of Nippon. London, 1932. Vol. 2. 358 p.

Yamashina Y. Note sur la Tetras falcipenne de Siberie // L'oiseau et la revue française d'ornithologie. 1939. Vol. 9. P. 3-9. 


\title{
NESTING BIOLOGY OF THE ASIAN SPRUCE GROUSE FALCIPENNIS FALCIPENNIS HARTLAUB, 1855 IN THE UPLAND PART OF ITS DISTRIBUTION RANGE
}

\author{
A. V. Andreev
}

\author{
Institute of Biological Problems of the North, FEB RAS, Magadan
}

\begin{abstract}
Radiotracking of 18 Asian Spruce Grouse hens revealed specific features of the species nesting biology in the central part of its contemporary distribution range. In the mountain taiga of AmurAmgun' interfluve area, the density averaged $4-5$ nests $/ \mathrm{km}^{2}$. In hens, the longevity of reproduction period, from visiting leeks and copulation to brood dispersion, reached 120-135 days. Dispersion of female spring congregations occurred by late April, with 250 to $1500 \mathrm{~m}$ (mean appr. $600 \mathrm{~m}$ ) distances between spring and nesting home ranges; the high season in the local population peaked by 3-5 May; the incubation proceeded 18 May through 14 June; the brood dispersion, mid- to late September. The clutch size varied from 5-7 eggs (mean 5.7); the incubation period lasted 23.5 days. During the incubation, sitting hens departed clutches 2-3 times/day; the departures lasted $15-115 \mathrm{~min}$ (27.9 $\mathrm{min}$ on the average ); the index of nest attendance reached 0.95 . During the entire course of incubation, the hens maintained stable clutch temperature with the gradient $4.1^{\circ} \mathrm{C} / \mathrm{cm}$. By the time of clutch formation, the hens fed mostly on sprouting larch needles; during the continuous incubation, they preferred bulky buds of fresh spruce needles. Up to $50 \%$ of nests were predated, and up to $50 \%$ of broods perished before dispersion.
\end{abstract}

Keywords: Sharp-winged Grouse, nesting, breeding success, Priamurye.

\section{REFERENCES}

Andreev, A. V., 1990, Observations on the Winter Biology of Sharp-Winged Grouse (Falcipennis falcipennis) in Priamurye, Zoologicheskii Journal, 69, 3, 69-80 [In Russian].

Andreev, A. V., 1999, Ecological Energetics and Survival of Birds in Extreme Environments, XXII IOC Plenary Lectures, Ostrich, 70 (1), 13-22.

Andreev, A. V., 2005, Nesting Biology of Asian Spruce Grouse, $X^{\text {th }}$ Int. Symposium on Grouse $26-30^{\text {th }}$ Sep. 2005, Luchon, 3-4.

Andreev, A. V.; Hafner, F., 2011, Winter Biology of the Siberian Grouse, Falcipennis falcipennis, Ornithological Science, 10, 87-97.

Andreev, A. V.; Hafner, F.; Klaus, S.; Gossow, H., 2001, Displaying Behaviour and Mating System in the Siberian Spruce Grouse (Falcipennis falcipennis Hartlaub, 1855), Journal für Ornithologie, 142, 404-424.

Boag, D. A.; Schroeder, M. A., 1992, Spruce Grouse, The Birds of North America, Eds. A. Poole, P. Stettenheim, F. Gill, Philadelphia, 5.

Ellison, L. N.; Weeden, R. B., 1979, Seasonal and Local Weights of Alaskan Spruce Grouse, Journal of Wildlife Management, 43, 176-183.

Hafner, F.; Andreev, A. V., 1998, Das Sichelhuhn, Klagenfurt - St. Petersburg.

Herzog, P. W., 1978, Food Selection by Female Spruce Grouse during Incubation, Journal of Wildlife Management, 42, 632-636.

Herzog, P. W.; Boag, D. A., 1977, Seasonal Changes in Aggressive Behavior of Female Spruce Grouse, Canadian Journal of Zoology, 55, 1734-1739.

Hjorth, I., 1970, Reproductive Behaviour in Tetraonidae with Special Reference to Males Viltrevy, 7, 4, 183-596.

Keppie, D. M., 1982, A Difference in Production and Associated Events in Two Races of Spruce Grouse, Canadian Journal of Zoology, 60 (9), 2116-2123.
Klaus, S.; Andreev, A. V., 2003, Falcipennis falcipennis (Hartlaub, 1855) Sichelhuhn, Atlas der Verbreitung Palaearktischer Vögel, 20, 1-5.

Klaus, S.; Lieser, M.; Suchant, R.; Andreev, A. V., 1995, Beitrag zur Kenntnis der Waldvegetation in der Fernostlischen Taiga Russlands (Amurregion), Allgemeine Forstzeitschruft, 14, 744-748.

Konovalenko, K., 2012, The Influence of Forest Cover Changes in Russian Far East on the Population of Siberian Spruce Grouse, Ms. Thesis, Albert-Ludwig Universität, Faculty of Forest and Environmental Sciences.

Mc. Court, K. H.; Boag, D. A.; Keppie, D. M., 1973, Female Spruce Grouse Activity during Laying and Incubation, The Auk, 90, 619-623.

Naylor, B. J.; Bendell, J. F., 1989, Clutch Size and Egg Size of Spruce Grouse in Relation to Spring Diet, Food Supply, and Endogenous Resources, Canadian Journal of Zoology, 67, 969-980.

Potapov, R. L., 1970, Comparative Review of Spruce Grouses (Genera Falcipennis and Canachites, Tetraonidae) of Asia and North America, Trudy Zoologicheskogo Instituta AS USSR, 47, 205-235 [In Russian].

Potapov, R. L., 1985, Order Galliformes, Family Tetraondiae, Leningrad, Nauka [In Russian].

Pukinsky, Yu. B., 2003, Nesting Life of the Bikin River Basin Birds, St. Petersburg, SPb University Press (Trudy Sankt-Peterburgskogo Obshchestva Yestestvoispytateley. Ser. 4, 86) [In Russian].

Robinson, W.L., 1980, Fool Hen: the Spruce Grouse on the Yellow Dog Plains, Madison, University of Wisconsin Press.

Stepanyan, L. S., 1962, Systematic Relations between the Sharp-Winged and Canada Grouse, Ornithology, 5, 368-371 [In Russian].

Taka-Tsukasa, N., 1932, The Birds of Nippon, London, 2.

Yamashina, Y., 1939, Note Sur la Tetras Falcipenne de Siberie, L'oiseau et la revue française d'ornithologie, 9, 3-9. 